\title{
Using Science Standards to guide the development of high school linguistics
}

\author{
Stephanie Joy Gamble Morse*
}

\begin{abstract}
As the linguistics community is pushing for more introductory classes to be taught at the high school level, it is useful to create a course framework. This framework can help provide structure for a potential Advanced Placement (AP) test and course as well as help interested teachers create successful proposals to add linguistics to their school's course offerings. Rather than reinventing the wheel, I suggest that the existing Next Generation Science Standards (NGSS) are an ideal starting point. Although not a science in the traditional secondary school sense, there is considerable overlap in methodology. Using the language of science can help those unfamiliar with linguistics see that it is the systematic study of language rather than just language learning, as well as help students transfer some of the skills and knowledge of practices that they already know from previous classes. This paper serves as an introduction to NGSS and the connections between the existing science standards and methodologies with the goal of demonstrating their usefulness for creating standards for linguistics.
\end{abstract}

Keywords. Advanced Placement; teaching linguistics; standards

1. Introduction. One of the major differences in teaching at the post-secondary versus secondary level is the need for a standardized set of content standards. While universities and colleges go through accreditation processes both at the organizational and programmatic level, as long as basic requirements are met, there is considerable flexibility in what gets taught. An introductory linguistics class at University of Michigan will cover largely the same material as a course of the same title at University of California, Santa Barbara, but they will emphasize different aspects of the field tailored to the focus of their department as well as the structure of their terms.

At the high school level, there are national and state standards for all grade levels and content areas. Many readers will be familiar with the Common Core standards for mathematics and English language arts which have been adopted by the majority of states in the United States. Though they are not without their detractors, the Common Core standards were put in place to help ensure that students across the US are working towards the same goal of preparing all students to be ready for college or a career.

Even if the state has not adopted the national standards, every state board of education has a set of standards for every subject. As a science teacher in Colorado, I'm currently one of many teachers working on our district's transition to the Next Generation Science Standards (NGSS). As a former graduate student in linguistics and a current high school science teacher, I see strong parallels between the two disciplines and believe that using the NGSS framework offers those of us interested in getting linguistics into more high school classrooms an excellent starting point to help develop standards and frameworks that will help the courses be accepted by districts, the College Board, and universities alike.

\footnotetext{
* Thanks to Mary Hudgens Henderson and Nicoleta Bateman for organizing this panel and proceedings and to all the teachers, professors and staff working hard to teach students the joys of linguistic inquiry. Author: Stephanie Joy Gamble Morse, Brighton High School (sjgmorse@gmail.com).
} 
There are two major reasons that developing standards for a high school linguistics class is important. The first of which is that getting approval from the College Board for an Advanced Placement (AP) test requires a standardized curriculum. According to the College Board, some of the requirements for creating a new class include: "determin[ing] the general content and ability level of each exam", "determin[ing] the requirements for the course syllabi" and "writ[ing] and review[ing] the course and exam descriptions" (College Board 2021). This paper offers some suggestions on how we can leverage existing frameworks to help move forward on the latter two requirements.

While Advanced Placement might be a goal, not all high school linguistics classes have to be AP courses. In fact, an introductory course in linguistics can be a very impactful class for students who may not be on the college-bound track. With carefully delineated standards, it will be much easier to work with school and district-level administration to get the new classes put in place for a variety of learners.

2. Why use science as a starting point? Linguistics is an incredibly broad field with subdisciplines ranging from computational data projects to more anthropological pursuits. While there are methodological differences between the subdisciplines, the Linguistic Society of America states that what linguists do is a science. "Linguistics is the science of language, and linguists are scientists who apply the scientific method to questions about the nature and function of language. Linguists conduct formal studies of speech sounds, grammatical structures, and meaning across all the world's over 6,000 languages" (Linguistic Society of America, n.d.).

My proposal, therefore, is that if we want others to see linguistics as a science, then it makes sense to use aspects of the existing science standards and frameworks to create a framework for teaching linguistics in the secondary classroom.

From an administrative perspective, using a familiar framework can be beneficial to getting a linguistics course approved in a school district or school. I have created proposals for an introductory class twice in two different schools in Colorado: a public charter school, and a regular public school. Many administrators, like the general public, tend to think of linguistics as learning languages rather than the systematic study of language. With many demands on their time, it is helpful to be able to use the language of familiar standards to help communicate the goals, importance, and benefits of the new course.

Given the more flexible nature of charter schools, I was able to get the course approval for linguistics the first year I attempted it. Public high schools often move a little more slowly. I will be submitting a proposal for the second time this fall and I am cautiously optimistic for it to be approved. While one of the main reasons for the class's rejection the first time was unrelated to the subject, I have been talking with my administration to sell the class as a way to develop students' analytical and communication skills.

At the secondary level, there is also a lot of pressure to push students to demonstrate proficiency in core subjects like math, science, and English language arts. In one measure of science proficiency, the NAEP Science Assessment, only 22\% of twelfth-graders scored at or above proficient. (National Center for Education Statistics n.d.) With so many students struggling to become proficient in science, opportunities for developing these skills can be a welcome addition to a school's course offerings. Using the language and standards of science to teach linguistics offers a way to reinforce the methodology and practices, if not the specific content, of science.

Another challenge with introducing linguistics at the high school level is the unfamiliarity most students have with the subject. Unlike many of their other subjects and classes, linguistics 
is a subject that they will typically come into a high school class with relatively little background knowledge. Contrast this with math or science where their prior courses have been building knowledge for, in some cases, the better part of a decade. In order to move quickly and efficiently through a class, using the language and practices of a subject that they've already had nearly a decade of experience with can help them make connections more quickly. Students will come to our classes (hopefully) with the necessary analytical skills, but if we use different terminology for those skills, it can lead to both unnecessary confusion and feelings of being overwhelmed.

I know from my experience teaching and reinforcing mathematical concepts in science classes, that coordinating terminology and practices around problem solving with the math department can be hugely beneficial to students. Likewise, when teaching linguistics, we can leverage the existing competencies of the students to make what might seem unfamiliar at first, familiar. So, instead of having students get stuck because I ask them 'What is the total of $6+2$ ?" when they're used to hearing "What is the sum of $6+2$ ?", students can more efficiently process the question and come to the correct answer.

3. Next Generation Science Standards and the scientific method. When thinking of science standards, even teachers tend to think of the specific content to cover in a class like "How does our respiratory system work?" or "What evidence is there for the Big Bang theory?". There is a degree of that in the existing Next Generation Science Standards (NGSS), but the reason that they will work for linguistics as well is because they are focusing on the practices of science rather than merely the facts of the discipline. If our goal is to teach students how to analyze linguistic data, our jobs can be made much easier by leveraging their existing competencies.

Most students, by the time they reach high school, will have been subjected to several iterations of the scientific method. Depending on the level, the model will vary in complexity, but the general pattern of asking a question and working through repeatable steps to try to get to an answer holds the same. This is generally the same process that we will try to follow in a large-scale inquiry in linguistics. Whether you're trying to figure out the rules governing reduplication in Anishinaabemowin or analyzing language trends on TikTok, the investigation will proceed along the same general track. We start with a question and ideally end with published results as seen in Figure 1.

The true strength in NGSS is that the standards are built around the practices and the skills used in conducting scientific investigations. These standards now focus on the how of science rather than being merely a long list of useful facts. According to the page on the development of NGSS, the authors justify the need for new standards by saying that "[s]cience education traditionally has focused on large volumes of content, primarily basic facts and vocabulary, while falling short on the deeper understanding of key scientific concepts and the application of these concepts to daily life. The NGSS calls for refocusing K-12 science to improve college preparation, STEM career readiness, and the ability of all members of society to make informed decisions" (National Science Teaching Association, n.d.). 


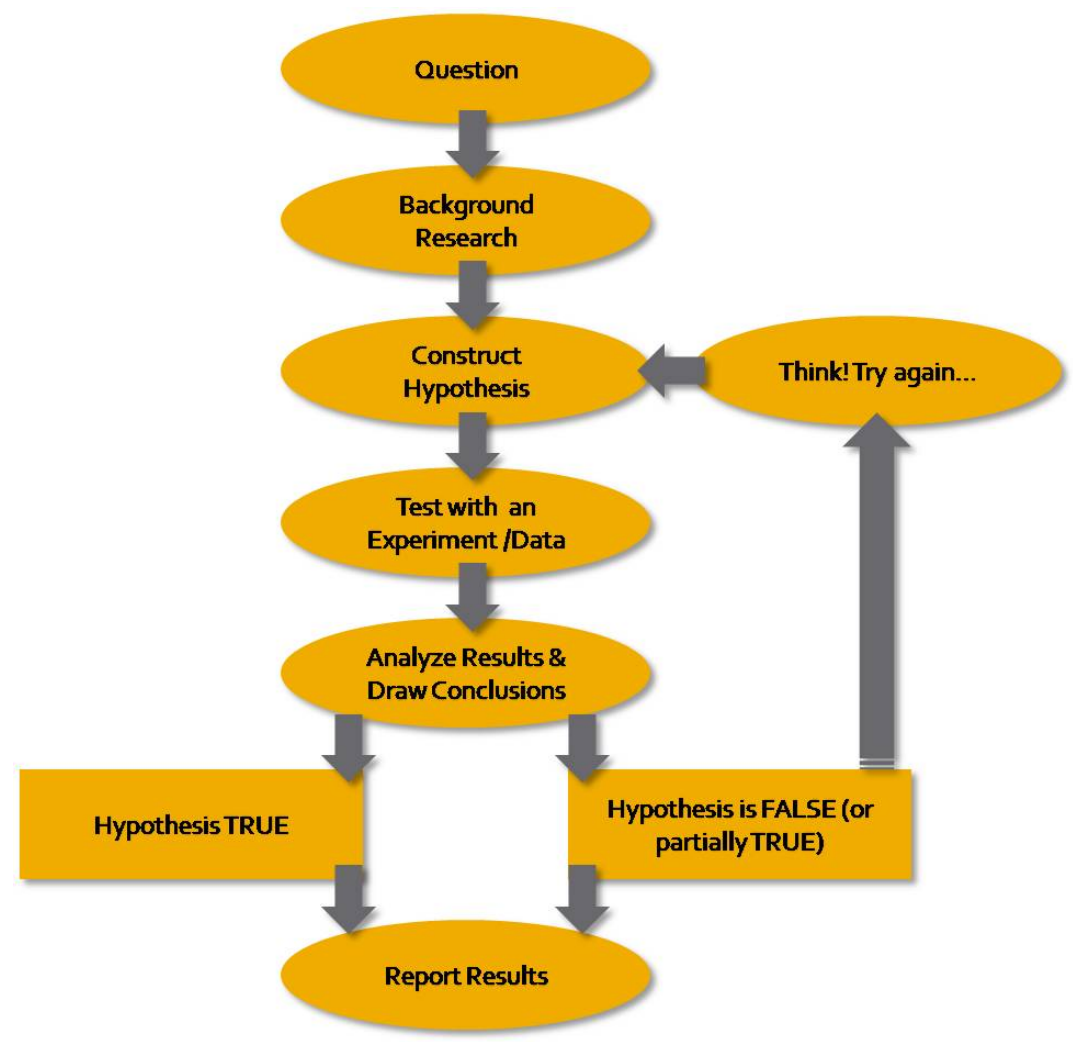

Figure 1. One version of the scientific method ${ }^{1}$

3.1. NGSS AND DCIS. There are three components to the standards: the disciplinary core ideas (DCIs), the practices, and the crosscutting concepts. The disciplinary core ideas are, as the name suggests, the key information for a subject area that changes from subject to subject. In science, these include big ideas like 'energy', 'heredity', and 'Earth's place in the universe'. For Linguistics, these might look like: 'morphology', 'phonetics', and 'syntax'. Each of the larger DCIs is comprised of several substandards that are framed as statements of what students should be able to do. For HS-ESS1-Earth's Place in the Universe, there are six specific skills that students should be able to show mastery of. Standard 1.3 states that students should be able to "Communicate scientific ideas about the way stars, over their life cycle, produce elements." and standard 1.6 says that students should be able to "Apply scientific reasoning and evidence from ancient Earth materials, meteorites, and other planetary surfaces to construct an account of Earth's formation and early history" (National Research Council 2012).

While in linguistics we do not particularly care about Earth's early history or the life cycle of stars beyond the specific meaning this might have to the speakers we're working with or a particular data set, we can see that the standards are all framed as being able to complete an action or demonstrate a skill that's relevant to the content. Rather than a list of facts that are relevant to the outcome, students are asked to communicate their ideas or apply reasoning and evidence. So, while the standard does not tell you the specific facts needed to get there, it provides the end goal for a student learning that particular skill. There is supporting

\footnotetext{
${ }^{1}$ Image from General Chemistry Supplement by Emily Eames

https://chem.libretexts.org/Bookshelves/General_Chemistry/Book\%3A_General_Chemistry_Supplement_(Eames).
} 
documentation that provides guidance on the facts needed, but strict memorization of those facts is no longer the emphasis of the standard. A student would need to understand how nucleosynthesis works, how gravity affects a star's life cycle, and what eventually leads to the death of a star to be able to create an argument on the formation of elements. But the goal is to have students be able to take those pieces and put them together into a coherent whole and demonstrate that they can do something with those separate pieces.

In an introductory linguistics class either at the college-prep, AP level, or at the college level, there are particular skills associated with each topic that is covered. If we had the DCI of morphological analysis, one of the substandards might look like "Apply reasoning and evidence to construct a model of morphological word formation in a language." To be able to do this, a student may need to understand concatenative and nonconcatenative formation, affixes and roots, and have a basic understanding of what types of morphological systems exist for plurality, TAM, and gender.

That is a lot of information for a single standard and could easily be a goal for a college level morphology class. Likewise, for the formation of elements in stars, there are several pieces that are left for more advanced courses. Because of this, the NGSS DCI descriptions also offer boundary statements to put limits on what is actually needed to be considered as having mastery of a particular skill at a given level. Students describing the formation of elements within stars need to know that there is fusion of hydrogen into helium occurring in its core, but they do not need to know the details of the specific pathways in which this occurs. A boundary statement for the morphological analysis standard might specifically exclude alignment systems or put limits on which types of TAM markers to include. This is not to say that teachers wouldn't be able to bring in their favorite language examples or to use specific examples from languages spoken by their students; the statements would be there to help guide what is essential for the skill and what students should reasonably be expected to know for an Advanced Placement test.

3.2. NGSS PRACTICES. The second piece of the NGSS could be borrowed almost whole cloth. NGSS outlines eight practices that students should be able to incorporate by the time they complete their secondary schooling. While the DCI are the what of the standards, the practices illustrate how students will be expected to demonstrate competence in a given subject or subject area. These eight practices are:

- Asking questions

- Developing and using models

- Planning and carrying out investigations

- Analyzing and interpreting data

- Using math and computational thinking

- Constructing an explanation

- Engaging in an argument stemming from evidence

- Obtaining, evaluating, and communicating information

Most of these practices are key to being able to effectively perform and communicate linguistic analysis. If you notice from the earlier examples of the science standards, these practices are integrated into each of the content standards. While an introductory linguistics class may not delve deeply into corpus linguistics or other forms of statistics, all of the other practices are key to conducting a linguistic investigation and can be used to help write new standards for linguistics. Teaching the International Phonetic Alphabet is often a key topic in an introductory class, so the practice involved in simply being able to use the IPA would be 'developing and 
using models'. The standard might look like "Use place, manner, and voicing information to create a model of a language's phonetic inventory".

3.3. NGSS CROSSCUTTING CONCEPTS. This is the area where we can draw the strongest connections between linguistics and science and provide the greatest reinforcement. The crosscutting concepts are the big picture themes that are common to most, if not all of the DCIs. They are:

- Patterns

- Cause and effect

- Scale, proportion, and quantity

- Systems and system models

- Energy and matter

- Structure and function

- Stability and change

Here we also see some clear connections to what we do in linguistics, particularly with 'patterns', 'systems and system models', 'structure and function', and 'stability and change'. There are weaker connections in this section as well, such as 'energy and matter' and 'scale', but they could easily be dropped.

Even though this is where we can see some of the most natural connections to what linguists do and what we want to teach, this part of NGSS is likely the least useful for day-to-day lessons given the level of abstraction. Teachers are not typically going to create a lesson starting with "Today, we are going to learn about system models", but we will teach multiple lessons in multiple areas that touch on and reinforce the same concept.

The crosscutting concepts can also be a valuable part of the pitch to administration and for prompting students to use what they already know. Assuming a student has already taken a biology class, if you're having a discussion on the historical changes that lead to one of the current varieties of English, the students should already have a grounding in evolution. They will likely know that there are some things that remain relatively constant over time, like the tetrapod limb bone structure, and some features that can change rapidly depending on circumstances, like coloration. This is a direct example of stability and change. We can look at a lot of linguistic features through that lens and answer a lot of interesting questions. How stable are different categories or words, sounds, or grammatical features? Or, more broadly, how do languages change over time and why?

The students' knowledge of biological systems like the digestive system gives them the idea that there are many things in nature that are a collection of smaller systems working together for a greater effect. Language is just that, a complex natural system that is composed of many, similarly complex subsystems. We can use what they know of different organs having different structures for different functions to help frame discussions on not just the different aspects of language, but what they do to help convey meaning.

I am giving specific examples of science content to illustrate the connections, and it would be impractical for most teachers to be well-versed in the core sciences as well as linguistics. But a teacher would not have to know the specifics of the content to use these basic overarching ideas. Making the connections between a linguistics class and their prior science knowledge can be as simple as asking leading questions. For instance, if you are trying to elicit the idea of patterns, you could ask "What's an example of a pattern you've seen in one of your classes?" After several responses, some of which will likely be commentary on the fashion choices of 
others, the class can come up with a working understanding of what constitutes a pattern before diving into their first data sets. Thinking in abstract terms can be difficult for some students, so starting with concrete examples can help to prime the pump for them to look at language data.

This may be more or less necessary depending on the background of your students. If your class consists of entirely upper-level honors students, they may not need as many prompts. But, if the class has a higher number of typical or even lower-performing students, then this can be an extremely valuable exercise. Because the school was so small, I had already taught, or was currently teaching over half of the students in science. Especially for the ones who had taken Environmental Science with me, I had a good idea of their reasoning abilities and their pattern matching skills.

4. Example from the classroom. As mentioned above, I taught a linguistics class at a public charter school in Colorado. Both the school and, consequently, my class were fairly small. I had the luxury of teaching only 16 students in that class. The challenge was that I had a wide range of ability levels. I had two very sharp honors students, two students with truancy challenges, and one student with memory and processing issues, with the others being fairly typical learners. The class had been open to anyone who was interested, but the counselors had seen it as a class designed to improve the skills of English language learners. Of the two students who came in with fairly low skills, one decided to stay and one decided to drop.

While doing my student teaching in Santa Barbara, I had worked with an advisory class that was going through the SKILLS program (School Kids Investigating Language in Life and Society) that was created as an outreach program based out of University of California, Santa Barbara. ${ }^{2}$ While I had been more of a structural linguist, I had seen just how passionate some of the students got when they were working on a project where they were able to take a close look at their own life and connect it to bigger issues. When I designed my class, I wanted an integral part to also be a bigger, student-led investigation.

The first assignment that my students received was a language log. Every day, their homework was to notice something about language in the world around them and record it. It did not matter what they were noticing, just that they were taking the time to start paying attention. Every week they got a new log and I held on to them until they had completed 6 or 7 weeks' worth of logs. In the meantime, we were working on a variety of structural topics, so sometimes the students noticed related phenomena, but they were still mostly in listening mode.

At the end of those first few months, I returned their observation sheets and asked them to start to examine what they were noticing and to look for patterns in their data. From there we were able to use the scientific method to guide their projects. From the data collection process, to analysis and write up, they were actually able to more authentically follow the process of scientific inquiry than we are able to in a typical science class.

I saw the reasoning abilities of the students increase across both classes, especially for the students who came to me with significant skills deficits. I would want more years of this project to be more certain of assumptions, but I think that the opportunity for students to ask their own questions and define their own research in linguistics made them more comfortable asking questions in their science classes. Going through the scientific research process, practicing asking questions, and doing a project that mattered to them not only built their analytical skills but built up their confidence in being able to tackle complex problems.

\footnotetext{
${ }^{2}$ For more information on the SKILLS program, you can visit their website: https://www.skills.ucsb.edu/.
} 
5. Conclusion. As the linguistics community moves forward to create an Advanced Placement test and pushes for the inclusion of linguistics at the high school level, there is a need for creating standards for the courses. Although new standards could be written without using much from existing frameworks, the Next Generation Science Standards are an extremely helpful starting point.

There are clearly some aspects of NGSS that cleanly dovetail with linguistics, but there are others that are not such a straightforward fit. As someone who has taught both linguistics and science, I strongly suggest using NGSS as a starting point. Adaptations will be needed, but using terminology and language that students are more familiar with should help accelerate their learning in a new and unfamiliar content area. Using the language of NGSS will also help school and district administration see the benefits of linguistics to their students so that the course approval process can be more streamlined.

The Next Generation Science Standards are a great fit for linguistics because they focus on the practices and skills of the discipline, rather than just the content matter. If linguistics is to be treated as a science, it follows that we would want to use as many of those skills and practices as are relevant to an introductory-level course.

\section{References}

College Board. 2021. Course development. AP Central. Retrieved February 5, 2021 from https://apcentral.collegeboard.org/courses/how-ap-develops-courses-and-exams/coursedevelopment.

Linguistic Society of America. n.d. The science of linguistics. Retrieved January 04, 2021, from https://www.linguisticsociety.org/resource/science-linguistics.

National Center for Education Statistics. n.d. NAEP report card: 2019 NAEP science assessment. The nation's report card. Retrieved November 19, 2021. https://www.nationsreportcard.gov/highlights/science/2019/.

National Research Council. 2012. A framework for K-12 science education: Practices, crosscutting concepts, and core ideas. Washington, DC: The National Academies Press. https://doi.org/10.17226/13165.

National Science Teaching Association. n.d. The development of the Next Generation Science Standards. Retrieved January 04, 2021, from https://www.nsta.org/development-nextgeneration-science-standards.

NGSS Lead States. 2013. Next Generation Science Standards: For states, by states. Retrieved January 08,2021 , from https://www.nextgenscience.org/. 